\title{
Produção Científica sobre Esfera Pública: um Estudo Bibliométrico em Múltiplas Áreas do Conhecimento (1970-2015)
}

\author{
Scientific Production on Public Sphere: a Bibliometric Study in Multiple Areas of Knowledge (1970-2015)
}

Producción Científica sobre Esfera Pública: un Estudio Bibliométrico en Múltiplas Áreas del Conocimiento (1970-2015)

André Spuri Garcia

Doutorando em Administração (Concentração em Administração Pública) pela Universidade Federal de Lavras - UFLA Discente do Programa de Pós-Graduação em Administração (PPGA) do Departamento de Administração e Economia (DAE) da Universidade Federal de Lavras (UFLA)

http://lattes.cnpq.br/0538124964852647 https://orcid.org/0000-0001-5663-3585 andrespurigarcia@gmail.com Universidade Federal de Lavras (UFLA), Departamento de Administração e Economia (DAE), Caixa postal 3037, CEP 37200-000, Lavras, MG, Brasil. Telefone: (35) 3829-1441

José Roberto Pereira Doutor em Sociologia pela Universidade de Brasília - UnB. Pós-Doutor em Ciências Sociais pelo Centro de Estudos Sociais da Universidade de Coimbra. Professor Titular do Departamento de Administração e Economia http://lattes.cnpq.br/9219649053207449 http://orcid.org/0000-0003-1570-2016 jrobertopereira2013@gmail.com

Valderí de Castro Alcântara

Doutorado em Administração (Concentração em Administração Pública) pela Universidade Federal de Lavras - UFLA Discente do Programa de Pós-Graduação em Administração (PPGA) do Departamento de Administração e Economia (DAE) da Universidade Federal de Lavras (UFLA) http://lattes.cnpq.br/2870598651094370 http://orcid.org/0000-0002-6698-0609 valderidecastroalcantara@gmail.com

José Willer do Prado Doutorando em Administração (Concentração em Administração Financeira e controladoria) pela Universidade Federal de Lavras - UFLA Discente do Programa de Pós-Graduação em Administração (PPGA) do Departamento de Administração e Economia (DAE) da Universidade Federal de Lavras (UFLA) http://lattes.cnpq.br/0368409333816349 http://orcid.org/0000-0003-3926-2406 jwprado@gmail.com

RESUMO: O objetivo deste artigo foi analisar como se configura o campo de pesquisas sobre esfera pública. A pesquisa foi desenvolvida como um estudo bibliométrico por meio da base de dados Web of Science. Em síntese, o estudo demonstra que o campo de publicações em esfera pública é interdisciplinar, amplo e que ainda está em crescimento, principalmente a partir da década de 1990. Constatou-se que, além de ser autor do artigo mais citado, o filósofo Jürgen Habermas aparece como a principal referência bibliográfica do campo, mesmo com uma diversidade de críticas - como relevantes na base intelectual aparecem ainda Fraser (1992) e Calhoun (1992). Os resultados deste trabalho podem orientar e embasar novas discussões teóricas e pesquisas empíricas, dentre elas, aquelas sobre os processos econômicos, sociais e políticos em cursos atualmente no Brasil - e contribuir com os campos de pesquisa da administração pública e gestão social.

PALAVRAS-CHAVE: Habermas, Democracia, Frente de Pesquisa, Base Intelectual.
ABSTRACT: The objective of this article was analyzed as it configures the field of publications on public sphere. The research was developed as a bibliometric study through the Web of Science database. In summary, the study shows that the field of publications in the public sphere is interdisciplinary, broad and still growing, especially since the 1990s. It was found that besides the author of the most cited article, the philosopher Jürgen Habermas appears as a main bibliographical reference of the field, even with a diversity of criticisms. As relevant on the intellectual basis still appears Fraser (1992) and Calhoun (1992). The results of this work may guide and support new theoretical discussions and empirical researches, including those on economic, social and political processes in Brazilian courses - and contribute to the research fields of public administration and socia management.

KEY WORDS: Public Sphere, Democracy, Research Front, Intellectual Base.
RESUMEN: El objetivo de este artículo fue analizar cómo se configura el campo de investigaciones sobre esfera pública. La investigación fue desarrollada como un estudio bibliométrico a través de la base de datos Web of Science. En síntesis, el estudio demuestra que el campo de publicaciones en esfera pública es interdisciplinario, amplio y que aún está en crecimiento, principalmente a partir de la década de 1990. Se constató que además de ser autor del artículo más citado, el filósofo Jürgen Habermas, aparece como la principal referencia bibliográfica del campo, aun con una diversidad de críticas - como relevantes en la base intelectual aparecen todavía Fraser (1992) y Calhoun (1992). Los resultados de este trabajo pueden orientar y basar nuevas discusiones teóricas e investigaciones empíricas, entre ellas a aquellas sobre los procesos económicos, sociales y políticos en cursos actualmente en Brasil - y contribuir con los campos de investigación de la administración pública y de la gestión social.

PALABRAS CLAVE: Habermas, Democracia, Frente de Investigación, Base Intelectual.

Texto completo em português: http://www.apgs.ufv.br

Full text in Portuguese: http://www.apgs.ufv.br

\section{INTRODUÇÃO}

A categoria esfera pública é bastante referenciada na literatura e possui um percurso histórico e conceitual marcado por diferentes conceituações e vertentes (Fraser, 1992, Calhoun, 1992, Ferree, Gamson, Gerhards \& Rucht, 2002; Crossley \& Roberts, 2004, Koçan, 2008; Susen, 2011, Pereira, 2012). O filósofo frankfurtiano de segunda geração, Jürgen Habermas, é para uma ampla literatura o principal teórico desse grupo (Ferree et al., 2002; Lubenow, 2007; Koçan, 2008). Perlatto (2015, p. 123) indica isso ao afirmar: "A primeira formulação sistemática em torno do conceito de 'esfera pública' foi realizada por Habermas em sua tese de livre- 
docência, Mudança estrutural da esfera pública, publicada em 1962".

Entretanto, apesar da relevância, a esfera pública é um conceito com interpretação variável nas obras de Habermas (Lubenow, 2007). Os principais momentos de discussão são as obras conhecidas no Brasil como "Mudança estrutural da esfera pública: investigações quanto a uma categoria da sociedade burguesa" (original de 1962), "Teoria do agir comunicativo" (1981) e "Direito e democracia: entre facticidade e validade" (1992). Na primeira obra, Habermas (2003) apresenta como buscou na Inglaterra, França e Alemanha do século XVIII e XIX a formação de uma publicidade politizada e mostra o processo pelo qual ela despolitiza-se no século XX (Lubenow, 2007, Perlatto, 2015). De forma geral, o filósofo (2003) apresenta como a esfera pública influenciou a constituição dos Estados Nacionais por meio da formação de uma opinião pública que buscava a publicização das ações do Estado. Sendo assim, o autor utiliza a palavra öffentlichkeit que, segundo Lavalle (2002), seria propriamente traduzida como "publicidade". Ainda, é importante ressaltar que nas publicações inglesas utilizase mais o termo "public sphere" e no Brasil é mais comum o uso do termo "esfera pública" - apesar de algumas traduções utilizarem "espaço público" (Habermas, 2012).

Sabe-se, no entanto, que o conceito de esfera pública vai além das obras de Habermas (Calhoun, 1992, Crossley \& Roberts, 2004, Perlatto, 2015), sendo debatido por uma diversidade de autores ao pesquisar temas como democracia, movimentos sociais, opinião pública, relações entre Estado e sociedade civil, mídia, deliberação pública e participação social, sendo assim, categoria central de perspectivas contemporâneas da democracia (Avritzer \& Costa, 2004). Portanto, a hipótese inicial que parte dessa constatação é que a produção científica, em esfera pública, parece ser ampla e plural. Ressalta-se que no Brasil, além dos campos da sociologia e da ciência política (Avritzer \& Costa, 2004, Perlatto, 2015), esse conceito também ganhou destaque nos campos de administração pública, e, especificamente, gestão social (Tenório, 2005; Cançado, Pereira e Tenório, 2015).

Diante dessas considerações, torna-se relevante conhecer a produção acadêmica sobre a esfera pública: O número de publicações está crescendo? É uma temática interdisciplinar? Quais os autores mais citados e obras mais relevantes? Quais os periódicos mais atentos a temática e quais os debates centrais desenvolvidos a partir dela? Assim, a pergunta central deste artigo é: Como se configura o campo de pesquisas sobre esfera pública? Nesse sentido, o objetivo é analisar como se configura o campo de pesquisas sobre esfera pública. Para tanto, buscou-se a base de dados Web of Science para desenvolver uma pesquisa caracterizada como um estudo bibliométrico com a utilização o software CiteSpace (Chen, 2004, 2006) que, apesar das limitações, avalia a produção científica e permite identificar tendências, categorias emergentes, autores, obras e temáticas centrais (Prado Alcântara, Carvalho, Vieira, Machado, \& Tonelli, 2016). Além disso, o CiteSpace permite a visualização gráfica dos resultados (Niazi \& Hussain, 2011, Liu, 2013).
Após essa introdução (1), o artigo apresenta um breve escopo teórico sobre o tema (2), metodologia de pesquisa (3) e resultados (4). Por fim, são expostas as considerações finais (5), apontando implicações, limitações e recomendações do estudo.

\section{BREVE ESCOPO TEÓRICO}

O conceito de esfera pública ganhou grande destaque na segunda metade do século XX e é aplicado nas discussões sobre democracia, comunicação, movimentos sociais e sociedade civil, dentre outras temáticas (Avritzer \& Costa, 2004, Perlatto, 2015). Destaca-se que, nos últimos anos, conceitos de esfera pública foram incorporados à literatura da administração pública e gestão social e, nesse contexto, adentrou também no campo das ciências sociais aplicadas no Brasil (Tenório, 2005, Cançado, Pereira \& Tenório, 2015, Alcântara, 2015). Entretanto, em decorrência do destaque acadêmico, é um conceito com "[...] polissemia conceitual manifesta" (Ribeiro, 2012, p. 2) e marcado por várias contestações (Koçan, 2008).

Concepções de esfera púbica aparecem, apesar das diferenças, nas obras de Aristóteles, Hannah Arendt, Jürgen Habermas, Nancy Fraser, Charles Taylor, Niklas Luhmann, John Keane, Robert D. Putnam e outros (Ferree et al., 2002; Lubenow, 2007; Koçan, 2008). Segundo Koçan (2008), os conceitos de esfera pública permeiam significados micro e macro, isto é, significados que se pautam em interações entre indivíduos e aqueles que se concentram na interligação de indivíduos, instituições e estruturas. Além disso, existem teorias descritivas e normativas da esfera pública, em que: (a) teorias descritivas buscam explicar o que a esfera pública "é" e buscam analisar como o público afeta a vida política e social; e (b) teorias normativas que estão mais inclinadas a explicar o que a esfera pública "deve ser", baseando-se em princípios e pressupostos (Koçan, 2008; Silva, Garcia, Machado, Cruz \& Pereira, 2015). Koçan (2008) também trata de teorias da esfera pública orientadas para fins (oriented end) e para o agir (oriented act-oriented). Nas primeiras, existem metas que se quer alcançar no futuro, são procedimentais, deliberativas e discursivas, com foco no consenso e na razão - nessa teoria Habermas é o autor mais proeminente. Por outro lado, nas teorias oriented actoriented, as metas não são importantes, são reflexivas, heterogêneas, contestativas e com relevância para valores - aqui se destacam Arendt, Taylor e Fraser.

Por sua vez, Ferree et al. (2002) destacam quatro tradições de estudo da esfera pública: liberal representativa, liberal participativa, discursiva e construcionista. Os teóricos da esfera pública liberal representativa defendem a participação limitada e indireta, via representação, do público na esfera pública. John Stuart Mill e Edmund Burke são expoentes dessa tradição - mais recente são destaques Joseph Schumpeter, Anthony Downs e William Kornhauser. Por sua vez, teóricos da esfera pública liberal participativa defendem a inclusão popular e a participação ativa dos indivíduos na esfera pública, pois, conforme colocam Ferree et al. (2002, p. 295), "a participação aumenta a esfera pública, permitindo 
o surgimento de algo que se aproxima de uma vontade geral". São autores dessa tradição Paul Hirst e Benjamin Barber.

Assim como a tradição liberal participativa, a vertente discursiva da esfera pública também proclama a inclusão popular, a ampliação do público na esfera pública. Entretanto, central aqui é o processo de deliberação pública. Segundo Ferree et al. (2002), Habermas é a figura principal da tradição discursiva da esfera pública - além dele, são autores dessa prática Joshua Cohen, Amy Gutmann e Dennis Thompson. Se na vertente discursiva existe um otimismo em relação à deliberação, a vertente construcionista da esfera pública questiona o processo deliberativo, pois, consideram que as práticas discursivas são, também, práticas de manifestação de poder. Nisso, essa vertente questiona a possibilidade de igualdade no processo deliberativo. São expoentes da tradição construcionista Nancy Fraser, Seyla Benhabib e Iris Marion Young (Ferree et al., 2002). Há nessa vertente inspiração também em Hannah Arendt.

No Brasil, Habermas e Arendt parecem ser os autores mais referenciados quando se trata de debater esfera pública, com proeminência para o frankfurtiano. Recentemente, Silva et al. (2015) buscaram na literatura evidências teórico-empíricas da categoria esfera pública que fazem menção a Habermas. De acordo com os autores, essa categoria é pouco explorada no Brasil, mas, na literatura internacional, o campo encontra-se consolidado (não significando que seja consensual). Em relação à metodologia, a maioria dos estudos nacionais utiliza revisão de literatura e entrevista, com carência de pesquisas históricas. Silva et al. (2015, p. 13) ressaltam, ainda, que a maioria dos trabalhos analisados "buscou tratar de assuntos pontuais em determinadas regiões, setores ou até mesmo problema social". Adiante, em seu trabalho, os autores analisaram apenas 35 artigos e as palavras utilizadas para busca direcionaram os resultados para artigos empíricos, o que limita uma compreensão mais ampla do campo de publicações sobre esfera pública.

Finalmente o objetivo deste tópico foi apresentar um breve escopo teórico, dado que pelo design da pesquisa bibliométrica, o(a) leitor(a) terá acesso às discussões teóricas centrais do campo durante todo o texto.

\section{METODOLOGIA DE PESQUISA}

A revisão de literatura permite encontrar lacunas para pesquisas dentro de um determinado campo de conhecimento - a partir da qual pode-se delinear uma agenda de estudos (Prado et al., 2016). Para tanto, pode ser feita tanto em campos que possuem poucas publicações, como também nos quais têm um grande número de divulgações. É importante, porém, que ela seja justificada dentro de um contexto (Steward, 2004).

Em relação ao conceito de esfera pública, apesar de sua ampla utilização em diversos campos de conhecimento, ainda não foram encontradas revisões sistematizadas bibliométricas sobre o conceito, especialmente em grandes bases de dados e em periódicos com alto fator de impacto. No Brasil, trabalhos como os de Lubenow (2007) e Avritzer e Costa (2004) buscam reconstruir o conceito de esfera pública por meio da leitura de diversos autores como Habermas, Hannah Arendt, Nancy Fraser e Seyla Benhabib, mas não sistematizam a produção acadêmica internacional - o texto de Malmberg (2017) foca na recepção do conceito de esfera pública na Finlândia. Silva et al. (2015) realizaram uma revisão parcial focada apenas em trabalhos empíricos e que citam Habermas, portanto, apenas uma parte da ampla literatura sobre esfera pública foi acessada. Dessa forma, uma revisão como objetivada neste trabalho ainda não foi realizada. Além disso, nos últimos anos, a temática esfera pública vem sendo debatida no âmbito da administração pública e gestão social (Tenório, 2005, Cançado, Pereira \& Tenório, 2015, Alcântara, 2015) no Brasil e uma ampla sistematização da literatura internacional pode contribuir com novas possibilidades de pesquisas nesses campos, além de indicar aos pesquisadores a ampla trajetória do conceito, seus temas centrais, controvérsias, autores, periódicos - de outra forma, discussões sobre a frente de pesquisa e a base intelectual (Chen, 2004, 2006).

Por meio de um estudo bibliométrico, é possível descobrir, dentro de um conjunto de artigos (ou outras formas de publicação), quais são os autores mais citados, quais são as obras mais referenciadas, quais são as instituições e países que mais discutem determinado tema, quais são as palavras-chave mais utilizadas, quais são os periódicos que mais publicam e, ainda, acompanhar o número de publicações ao longo dos anos, dentre outras possibilidades (Pinto, Serra \& Ferreira, 2014, Liu, Yin, Liu \& Dunfor, 2015, Akhavan, Ebrahim, Fetrati \& Pezeshkan, 2016, Prado et al., 2016). Além disso, é possível utilizar de redes como análise complementar ou como forma de ilustrar os resultados, facilitando sua visualização e debate (Niazi \& Hussain, 2011, Liu, 2013, Prado et al., 2016). Para as buscas, realizou-se uma adaptação do framework proposto por Prado et al. (2016) - que orienta pesquisas bibliométricas, cientométricas e sociométricas (Quadro 1).

Seguindo as etapas do framework acima, para a coleta dos dados foi utilizada a base Web of Science da Thomson Reuters em decorrência do grande número de periódicos indexados, além de fornecer um padrão de operacionalização das buscas (Pinto, Serra \& Ferreira, 2014, Prado et al., 2016). É importante ressaltar que essa base possui poucos periódicos brasileiros e que não foi intenção do estudo fazer qualquer inferência de como a esfera pública é discutida nos estudos nacionais. Portanto, são limitações da pesquisa o foco geral e o conhecimento prévio de que a Web of Science indexa um número maior de periódicos do eixo Estados Unidos e Europa pela característica da base (Prado et al., 2016).

Para a busca, foi utilizada a expressão public sphere entre aspas no campo "título" do sistema de busca da Web of Science, ou seja, o termo deveria constar no título do artigo - não foram encontrados resultados para traduções da expressão em português ou alemão. Utilizou-se apenas essa expressão, dado que o objetivo era centrado no campo de pesquisa de esfera pública, que diverge do campo de pesquisa de espaço público na maioria de seus textos - em pesquisas futuras é coerente a ampliação para outras significações da palavra "público" em seus diversos usos - tal como a consideração de palavras como publicidade (Lavalle, 2002) e publicização (Lubenow, 2007). Adiante, foram considerados apenas documentos em formato de artigo científico, em todos os anos 
disponíveis na base até 2015 - o primeiro encontrado foi de 1970 -

e o artigo poderia estar em qualquer idioma e em qualquer área do conhecimento, resultando, assim, em 801 trabalhos encontrados.

Quadro 1: Etapas do estudo

\begin{tabular}{|c|c|c|c|}
\hline & Etapa & & Descrição \\
\hline \multirow{2}{*}{1} & \multirow{2}{*}{ Operacionalização } & 1.1 & Escolha da(s) base(s) científica(s) ou periódicos \\
\hline & & 1.2 & Delimitação dos termos que representam o campo \\
\hline \multirow{6}{*}{2} & \multirow{6}{*}{$\begin{array}{l}\text { Procedimentos de } \\
\text { busca }\end{array}$} & 2.1 & Title (termo do campo) \\
\hline & & 2.2 & Utilização de aspas: expressão exata \\
\hline & & 2.3 & Filtro 1: Delimitação em somente artigos \\
\hline & & 2.4 & Filtro 2: Todos os anos \\
\hline & & 2.5 & Filtro 3: Todas as áreas \\
\hline & & 2.6 & Filtro 4: Todos os idiomas \\
\hline \multirow{15}{*}{3} & \multirow{15}{*}{$\begin{array}{l}\text { Procedimentos de } \\
\text { seleção e análise da } \\
\text { produção científica }\end{array}$} & 3.1 & Download das referências - software EndNote \\
\hline & & 3.2 & Download das referências em formato planilha eletrônica \\
\hline & & 3.3 & Download das referências para utilização no CiteSpace \\
\hline & & 3.4 & Organização das referências no EndNote \\
\hline & & 3.5 & Organização de matriz de análise em planilha eletrônica \\
\hline & & 3.6 & Importação dos dados para softwares de análise \\
\hline & & 3.7 & Busca dos artigos completos \\
\hline & & 3.8 & Análise do volume das publicações e tendências temporais \\
\hline & & 3.9 & Análise das referências e artigos mais citados \\
\hline & & 3.10 & Análise do país de origem (do primeiro autor) \\
\hline & & 3.11 & Análise dos periódicos \\
\hline & & 3.12 & Análise da autoria e coautoria \\
\hline & & 3.13 & Análise das categorias (áreas) das publicações \\
\hline & & 3.14 & Análise das palavras-chave \\
\hline & & 3.15 & Descrição, estudo das relações e tendências \\
\hline
\end{tabular}

Fonte: Adaptado de Prado et al. (2016).

Em seguida, foi realizado download das referências para o software EndNote, download das referências em formato planilha eletrônica e download das referências para utilização no CiteSpace (Chen, 2004, 2006). Após isso, os dados foram organizados nesses softwares e em planilha eletrônica. As análises foram focadas no volume das publicações, tendências temporais, referências e artigos mais citados, país, autoria e coautoria, categorias (áreas) das publicações, palavras-chave, sínteses de artigos mais relevantes e estudo das relações e tendências - esse último item por meio do CiteSpace e análise gráfica do número de publicações. O CiteSpace permite a visualização gráfica da rede de relacionamento entre autores, obras, periódicos e palavras-chave, dentre outros critérios (Chen, 2004, 2006, Niazi \& Hussain, 2011, Liu, 2013).

Por meio do CiteSpace identifica-se a "frente de pesquisa" e a "base intelectual" do campo de pesquisa em estudo (Chen, 2004, 2006, Niazi \& Hussain, 2011, Liu, 2013), cabendo observar que aquela diz respeito à "emerging thematic trends and surges of new topics" (Chen, 2006, p. 362) e esta é representada pelas redes de cocitações de periódicos, autores e referências bibliográficas. Com esses procedimentos, é possível que pesquisador consiga visualizar a configuração inicial do campo de estudo, bem como pontos de virada teórica e temas emergentes de pesquisa (Chen, 2004, 2006).

\section{ESFERA PÚBlicA: FRENTE DE PESQUISA E BASE INTELECTUAL}

Primeiramente, na Figura 1, apresenta-se o número de publicações por ano. Percebe-se que, apesar de algumas oscilações, até o presente momento, existe uma tendência de crescimento no número de publicações - sendo 2015 o ano com maior número de artigos publicados (64 artigos). Essa análise mostra o quanto a temática esfera pública continua academicamente relevante, principalmente em um contexto mundial marcado por diversas manifestações e questionamentos teóricos e práticos dos modelos de democracia vigentes e das formas de relação entre Estado, mercado e sociedade (Goodman, 2010). Em especial, a esfera pública, atualmente, ganha discussões também pela relevância sociopolítica atual da internet (Papacharissi, 2002, Medeiros, 2013).

Figura 1: Número de artigos publicados por ano

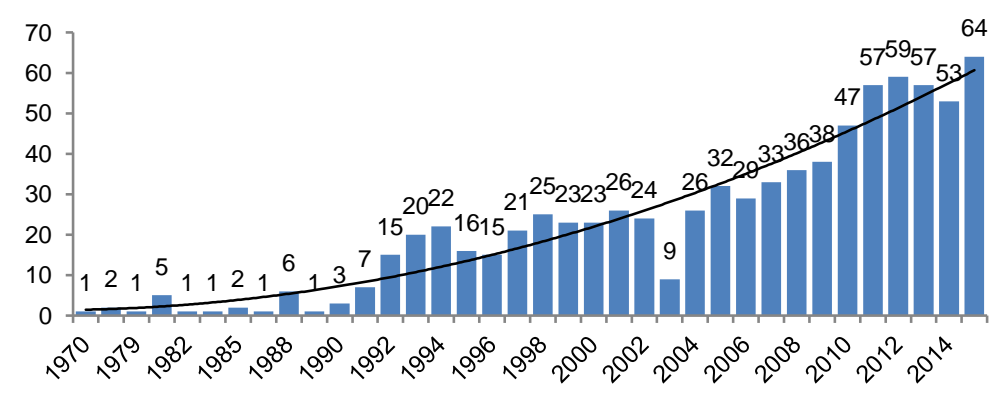

Nota: Linha de tendência quadrática com $R^{2}=0,92$. 
É destaque, também, que o primeiro artigo encontrado é de 1970 e que até o final da década de 1980 o número dessas pesquisas era relativamente baixo - o que indica como ocorreu incialmente a recepção do conceito (Malmberg, 2017). O primeiro artigo encontrado na busca foi Commitment is a red herring a discussion of minority business development to explore the role of the private sector in the public sphere (Beard, 1970) publicado no periódico Urban Affairs Quarterly. Na sequência, em 1975 foram publicados os artigos: The proletarian public sphere and political organization: an analysis of Oskar Negt and Alexander Kluge's the Public sphere and experience (Knödler-Bunte, 1975) e Classstructure and legitimatory public sphere: a hypothesis on the continued existence of class relationships and the problem of legitimation in transitional societies (Paris, 1975) - ambos no periódico New Germany Critique. Esses dois estudos debatem a obra de Habermas em oposição a outras, como as de Oskar Negt e Alexander Kluge. O debate gira em torno da esfera pública proletária, que Habermas (2003) teria ignorado na sua obra de 1962. Portanto, desde a década de 1970 já existiam controvérsias em torno da categoria esfera pública.

Observa-se, porém, um grande salto no número de publicações na década de 1990. Um possível motivo é a tradução para o inglês da obra de Jürgen Habermas, "Mudança Estrutural da Esfera Pública" em 1991 (The structural transformation of the public sphere: an inquiry into a category of bourgeois society). Outra razão possível e complementar é a tradução para o inglês de "Direito e
Democracia" em 1996 (Between facts and norms: contributions to a discourse theory of law and democracy). Segundo Malmberg (2017), a obra "Mudança estrutural da esfera pública" foi praticamente ignorada por cerca de 30 anos, até que ganhou tradução para o inglês - estudo que corrobora os achados deste artigo.

Adiante destaca-se que não houve concentração de publicações em um mesmo autor. Os autores com maior número de artigos foram Lincoln Dahlberg (cinco artigos), David Randall (quatro artigos) e M. Hansen (quatro artigos). Também não houve concentração de instituições dos autores, apenas as universidades University of Wisconsin e New York University aparecem com nove artigos, as demais aparecem com valores inferiores. Portanto, a frente de pesquisa é formada por uma diversidade de autores e universidades.

Na sequência, na Tabela 1 são apresentados os dez artigos mais citados (Cit.) da busca e, em seguida, são sintetizados. A análise dos artigos mais citados é importante, pois oferece uma noção inicial dos temas e dos autores que estão sendo discutidos portanto daquilo que Chen (2006) denomina de frente de pesquisa. Ademais, os artigos que figuram entre os mais citados geralmente oferecem discussões importantes e de grande relevância para determinada área de conhecimento e podem conforme apresentamos direcionar debates nos campos de administração pública e gestão social.

Tabela 1: Os dez artigos mais citados (citação indexada na base Web of Science)

\begin{tabular}{|c|c|c|}
\hline Título do artigo & Referência & Cit. \\
\hline Religion in the public sphere & Habermas (2006) & 220 \\
\hline The virtual sphere: The internet as a public sphere & Papacharissi (2002) & 206 \\
\hline $\begin{array}{l}\text { How events enter the public sphere: Conflict, location, and sponsorship in local newspaper } \\
\text { coverage of public events }\end{array}$ & Oliver e Myers (1999) & 144 \\
\hline $\begin{array}{l}\text { Transnationalizing the public sphere: On the legitimacy and efficacy of public opinion in a post- } \\
\text { Westphalian world }\end{array}$ & Fraser (2007) & 132 \\
\hline The new public sphere: Global civil society, communication networks, and global governance & Castells (2008) & 111 \\
\hline Imagining solidarity: Cosmopolitanism, constitutional patriotism, and the public sphere & Calhoun (2002) & 108 \\
\hline $\begin{array}{l}\text { Public sphere and private life - toward a synthesis of current historiographical approaches to the } \\
\text { old regime }\end{array}$ & Goodman (1992) & 106 \\
\hline $\begin{array}{l}\text { Whats political or cultural about political-culture and the public sphere: toward an historical } \\
\text { sociology of concept-formation }\end{array}$ & Somers (1995) & 97 \\
\hline Movements and media: Selection processes and evolutionary dynamics in the public sphere & Koopmans (2004) & 93 \\
\hline Public sphere civil society in China - the 3rd realm between state and society & Huang (1993) & 89 \\
\hline
\end{tabular}

Em Religion in the public sphere Habermas (2006) questiona a capacidade que os cidadãos têm de separar mentalmente razões religiosas e razões seculares, uma vez que muitas pessoas assentam suas vidas cotidianas baseadas em sua crença religiosa. Para o autor, se determinados indivíduos baseiam sua existência política e social na crença religiosa e, ao mesmo tempo, o Estado a permite como direito básico, este não pode esperar que todas as pessoas justifiquem suas decisões e argumentos com base na razão secular. Portanto, argumentos religiosos podem figurar na esfera pública política formal e informal, desde que sejam traduzidos, ou seja, transformem-se em uma razão secular. Entretanto, os religiosos devem aceitar a prioridade oferecida às razões seculares na arena política. Ou seja, eles devem aprender a desenvolver uma postura epistêmica em uma sociedade secular. Entretanto, Habermas destaca que não se devem excluir essas tradições que desencadeiam uma inspiração para toda sociedade. 
Para Papacharissi (2002), a internet e os novos meios de comunicação podem aumentar a democratização política ao adicionar às possibilidades de expressão política e, consequentemente, desenvolver cidadãos mais ativos politicamente. A internet é uma excelente fonte de informações e opiniões, alternativa aos tradicionais meios de comunicação (rádio, televisão) sempre questionados pela sua parcialidade e confluência com interesses econômicos e políticos. Por outro lado, esse autor destaca que os "céticos em relação à internet advogam que esta pode ocasionar o declínio da esfera pública por ser um recurso ainda não acessível universalmente", ou seja, existem pessoas que não possuem acesso à internet; pelo fato das discussões nesta serem fragmentadas e superficiais, e porque $o$ anonimato favorece à proliferação de "discursos de ódio". Nesse contexto, o trabalho de Papacharissi (2002) realiza um debate entre "céticos" e "otimistas" em relação ao potencial democratizante da internet e das novas tecnologias de comunicação. Finalmente Papacharissi (2002) destaca que é incerto o papel desse meio de comunicação como protagonista de uma mudança política.

Oliver e Myers (1999) buscaram analisar eventos públicos (marchas, protestos, manifestações, apresentações teatrais e musicais, comícios, etc.) e sua relação com a mídia. Segundo os autores, a vida pública ocorre em lugares públicos em que as pessoas podem debater "cara a cara" e influenciar um ao outro. Eles ressaltam que manifestações, protestos, entre outros eventos populares, buscam expressar um sentimento coletivo e influenciar a opinião pública, ou seja, tais eventos são importantes para a esfera pública. Destacam, ainda, que a mídia faz a ligação entre o "evento" e a esfera pública e que sem sua cobertura, aquele teria pouco poder de influenciar a opinião das pessoas. Nesse sentido, os meios de comunicação desempenham um papel fundamental na repercussão de um protesto. Os autores buscam discutir quais fatores influenciam a probabilidade de determinado evento público receber ou não cobertura da mídia. Os resultados mostraram que "manifestações" chamam mais sua atenção que os demais eventos públicos e que pautas conflituosas e polêmicas tendem a receber maior "atenção da mídia".

Fraser (2007) traz à tona a ideia de esfera pública transnacional, ou seja, arenas discursivas que não estão restritas aos limites de uma nação ou Estado. Segundo a autora, a teoria da esfera pública habermasiana, desde 1962, tem sido utilizada para um determinado território, para uma dada comunidade política. Em contrapartida, com a instabilidade geopolítica resultante da Guerra Fria e, mais recentemente, com o fenômeno da globalização, tornase necessário repensar o conceito de esfera pública em um contexto transnacional (Fraser, 2007).

Fraser (2007) dedica um tópico de seu texto para apresentar as características da esfera pública habermasiana, e para tal esforço utiliza a obra "Mudança Estrutural da Esfera Pública". Conforme à autora, o conceito de Habermas repousa sobre seis pressupostos teóricos-sociais que deixam claro o caráter nacional e ressalta, então, que Habermas conceituou a esfera pública tendo como projeto político a democratização do Estado-nação.
Contudo, Fraser (2007) destaca que nas sociedades contemporâneas os problemas não estão circunscritos a fronteira dos Estados territoriais. Aquecimento global, desemprego, guerra ao terrorismo, direitos humanos, por exemplo, são assuntos que extrapolam as fronteiras dos países. Nesse sentido, é necessário discutir sobre a esfera pública transnacional. A esfera pública transnacional traz novas indagações sobre legitimidade e eficácia: como interrogar a eficácia se a opinião pública não tem um destinatário certo? Como interrogar a legitimidade se a esfera pública não envolve apenas uma determinada comunidade política? Diante do exposto, Fraser (2007) destaca que é necessário repensar a legitimidade e eficácia em um contexto transnacional.

Castells (2008), assim como Fraser (2007), argumenta a necessidade de pensar em uma esfera pública internacional. A esfera pública existe, segundo Castells (2008), dentro de um espaço político/institucional que não está sujeito ao controle de um poder soberano em particular. Ainda, esse autor reconhece a existência de interesses sociais que são expressos em nível mundial como, por exemplo, as religiões, aquecimento global, direitos humanos, segurança global, terrorismo, armas químicas, entre outros. Reconhece, ainda, a existência de uma sociedade global, de uma governança global representada por instituições políticas internacionais - ONU, FMI, entre outras. Ademais, para ele, a globalização causa, ainda, uma crise de identidade nos Estados-nação e uma crise de equidade com a desregulamentação dos mercados. Consoante com Castells (2008), portanto, se for reconhecida a existência de instituições e atores globais, o mesmo tipo de esfera pública idealizada por Habermas para o âmbito nacional deve, nas sociedades contemporâneas, ser expandido para um nível transnacional. Entretanto, esse debate ainda não está claro, ou seja, as condições de existência desta esfera transnacional ainda não estão evidentes.

Calhoun (2002) também trabalha com a globalização e a ideia de uma esfera pública internacional. De acordo com o autor, a globalização é vendida como progresso, como uma necessidade. Concomitantemente, alternativas a ela são vistas como regresso. Ele busca, portanto, discutir aspectos do discurso dominante sobre a necessidade de globalização e, além disso, procura discutir a inadequação relacionada à construção da solidariedade social. Assim, debate com autores que defendem a ideia de uma sociedade transnacional. A intenção de Calhoun (2002) não é defender uma ideia antiglobalização, apenas problematizar questões que a consideram relevantes.

A esfera pública não deve ser considerada, segundo Calhoum (2002), apenas um espaço de discussões e tomadas de decisões racionais, mas, também, um lugar de construção de solidariedade social e política e defende que é necessário observar as implicações da globalização para esta construção. Tratar o nacionalismo como algo ultrapassado é deixar de reconhecer seus pontos positivos (Calhoun, 2002). O autor dialoga com Habermas ao longo de todo texto, discutindo assuntos como globalização, esfera pública, racionalidade e identidade cultural. Calhoun (2002) destaca que a esfera pública é composta também de questões 
relacionadas à identidade e a cultura e questiona, portanto, como pensar a legitimidade de tal no âmbito internacional.

Goodman (1992) estudou a relação entre esfera pública e esfera/vida privada no Antigo Regime. A data em que escreveu o texto foi oportuna para tal debate, pois as obras "Mudança Estrutural da Esfera Pública" de Habermas e "A História da Vida Privada", editadas por Roger Chartier, tinham sido recémtraduzidas para o inglês. A autora, então, buscou um debate entre as obras mencionadas para mostrar que elas são complementares e que a esfera pública habermasiana é uma das dimensões da esfera privada de Chartier e seus colaboradores. Segundo Goodman (1992), a oposição rigorosa entre esfera pública e esfera privada não é válida. Conclui-se que, se atualmente as esferas pública e privada são esferas desacopladas, estas eram articuladas no período do Antigo Regime (Goodman, 1992). A autora dedica, ainda, algumas páginas para tratar da mulher na esfera pública.

Somers (1995) trabalha o conceito de cultura política que, segundo ela, esteve bastante presente nos estudos de ciência política e sociologia política nos anos 1950 e 1960 e que foi revivido por sociólogos e cientistas políticos nos anos 1980 e 1990. A autora destaca que o conceito foi associado quase que exclusivamente com as teorias de modernização parsonianas nos anos 1950 e 1960. A definição foi radicalmente criticada pelas ciências sociais durante os anos 1960 e 1970 e veio à tona novamente com a tradução, em 1989, da obra "Mudança Estrutural da Esfera Pública" de Habermas. De acordo com Somers (1995), o relato de Habermas sobre a esfera pública burguesa muito tem em comum com o conceito de cultura política utilizado nas teorias parsonianas (Somers, 1995). O que causa espanto na autora, é que o conceito de cultura política, em ambos os casos (Habermas e Parsons), é utilizado de uma forma que não é nem político e nem cultural. A autora busca, então, uma nova lente/abordagem/metodologia para compreender o conceito de cultura política. Sugere o uso de uma sociologia histórica da formação de conceitos (Somers, 1995).

Koopmans (2004) estuda as novas formas de interação entre movimentos sociais e autoridades políticas. $\mathrm{O}$ autor argumenta que antes do advento do Estado-nação democrático essa interação era localizada, imediata e direta. Esta ainda não desapareceu por completo, entretanto, tornou-se mais rara. É difícil, nos dias de hoje, que os manifestantes tenham contato direto com seu destinatário. A mídia cumpre um papel importante nesta interação indireta. Koopmans (2004) ressalta que é por meio desta que ocorre a interação entre manifestantes e autoridades, assim, os movimentos e as autoridades políticas devem ganhar a simpatia daqueles que estão acompanhando os acontecimentos via mídia. Se determinado protesto não é relatado pelos meios de comunicação, há uma enorme chance de o destinatário nem tomar conhecimento deste.

Koopmans destacava em 2004 a ausência de debates teóricos aprofundados sobre o papel da mídia e seu impacto nos movimentos. O autor destaca que diariamente diversos grupos tentam inserir mensagens na esfera pública, mas a grande maioria é desconsiderada ou considerada ilegítima. Apenas aqueles que conseguem atrair a atenção dos meios de comunicação conseguem alcançar outros atores sociais. Nesse sentido, portanto, entende-se a esfera pública como um espaço limitado de comunicação e com um nível elevado de competição.

Fechando a lista dos dez artigos mais citados, Huang (1993) buscou estudar a esfera pública, a sociedade civil e a relação entre Estado e a sociedade chinesa. Inicia seu trabalho destacando que Habermas deu dois sentidos para o termo esfera pública: um mais específico, que trata da esfera pública burguesa; e outro mais geral, no qual a esfera pública burguesa é apenas uma variante. $\mathrm{O}$ autor cita Habermas em diversos momentos. Segundo Huang (1993), o problema de utilizar-se tal autor, no contexto chinês, é que uma de suas variantes, a esfera burguesa, é muito específica para ser utilizada na China e, em contrapartida, o conceito mais geral pode não ser útil para o específico nesse contexto. Esse texto é relevante ainda para mostrar o debate a partir do conceito de esfera pública em países não ocidentais como no caso da China. Em outro país oriental, no Japão, destaca-se os estudos de Arrington (2014) e Uchida (2013).

Em síntese, esses dez artigos focam em diversos temas, mas com recorrência para mídia, movimentos sociais e esfera pública transnacional. Constata-se, também, que além de ser autor do artigo mais citado (Religion in the public sphere - 220 vezes), Habermas aparece como a principal referência na maioria dos demais, tanto em artigos 'favoráveis' aos seus conceitos, como em artigos críticos a estes. Como controvérsia, aparece o texto de Nancy Fraser (2007), conhecida por debater a esfera pública habermasiana desde a década de 1990, especialmente com seu texto Rethinking the public sphere: a contribution to the critique of actually existing democracy, presente em Fraser (1990) e Fraser (1992).

No que se refere aos periódicos que mais publicaram, destacase que o maior número de artigos foi encontrado nos seguintes: Javnost-The Public, Public Culture, Media Culture \& Society e European Journal of Communication, conforme a Tabela 2. A análise destes é relevante de forma, também, pragmática, uma vez que o que permite aos pesquisadores encontrarem periódicos para busca e submissão de artigos sobre determinada temática, bem como entender onde se concentram as publicações.

Cabe destacar que Javnost - The Public é um periódico interdisciplinar que foi fundado em 1994 para tratar dos problemas da esfera pública nos níveis nacional e internacional e incentivar a pesquisa nesse campo de conhecimento. O periódico Public Culture (20 artigos) é do tipo interdisciplinar de estudos culturais e divulga textos sobre formas culturais da esfera pública e dos fluxos culturais globais. Media Cultura \& Society (18 artigos) apresenta discussões sobre meios de comunicação em diversos contextos históricos, políticos, sociais, econômicos e culturais. De forma geral, dos periódicos apresentados na tabela a maior parte tem foco em temas como mídia, cultura e sociedade. Pelos resultados, também observa-se que há pouca concentração, dado que os onze periódicos com maior número de artigos respondem por apenas $18,73 \%$ das publicações totais. Assim, a frente de pesquisa é formada especialmente pelos periódicos Javnost-The Public, Public Culture, Media Culture \& Society. 
Tabela 2: Periódicos que mais publicaram

\begin{tabular}{|c|c|c|}
\hline Periódico & Artigos & Proporção \\
\hline Javnost-The Public & 42 & $5,24 \%$ \\
\hline Public Culture & 20 & $2,50 \%$ \\
\hline Media Culture \& Society & 18 & $2,25 \%$ \\
\hline European Journal of Communication & 13 & $1,62 \%$ \\
\hline Media International Australia & 9 & $1,12 \%$ \\
\hline New German Critique & 9 & $1,12 \%$ \\
\hline Telos & 9 & $1,12 \%$ \\
\hline Eighteenth-Century Studies & 8 & $1,00 \%$ \\
\hline Theory Culture \& Society & 8 & $1,00 \%$ \\
\hline Social Science History & 7 & $0,87 \%$ \\
\hline Theory And Society & 7 & $0,87 \%$ \\
\hline Total parcial de artigos & 150 & $18,73 \%$ \\
\hline Artigos em outros periódicos & 651 & $81,27 \%$ \\
\hline Total de artigos & 801 & $100,00 \%$ \\
\hline
\end{tabular}

Continuando, a Figura 2 mostra as categorias da base Web of Science nas quais os artigos são enquadrados. Por meio do software CiteSpace foi possível visualizar uma linha do tempo e ver em que ano uma determinada categoria teve seu primeiro artigo utilizando o termo public sphere no título. As categorias permitem inferir em que áreas das ciências determinada temática tem sido estudada - e consequentemente verificar se é um termo disciplinar ou multi/interdisciplinar.

Figura 2: Categorias do Web of Science (Web of Science category)

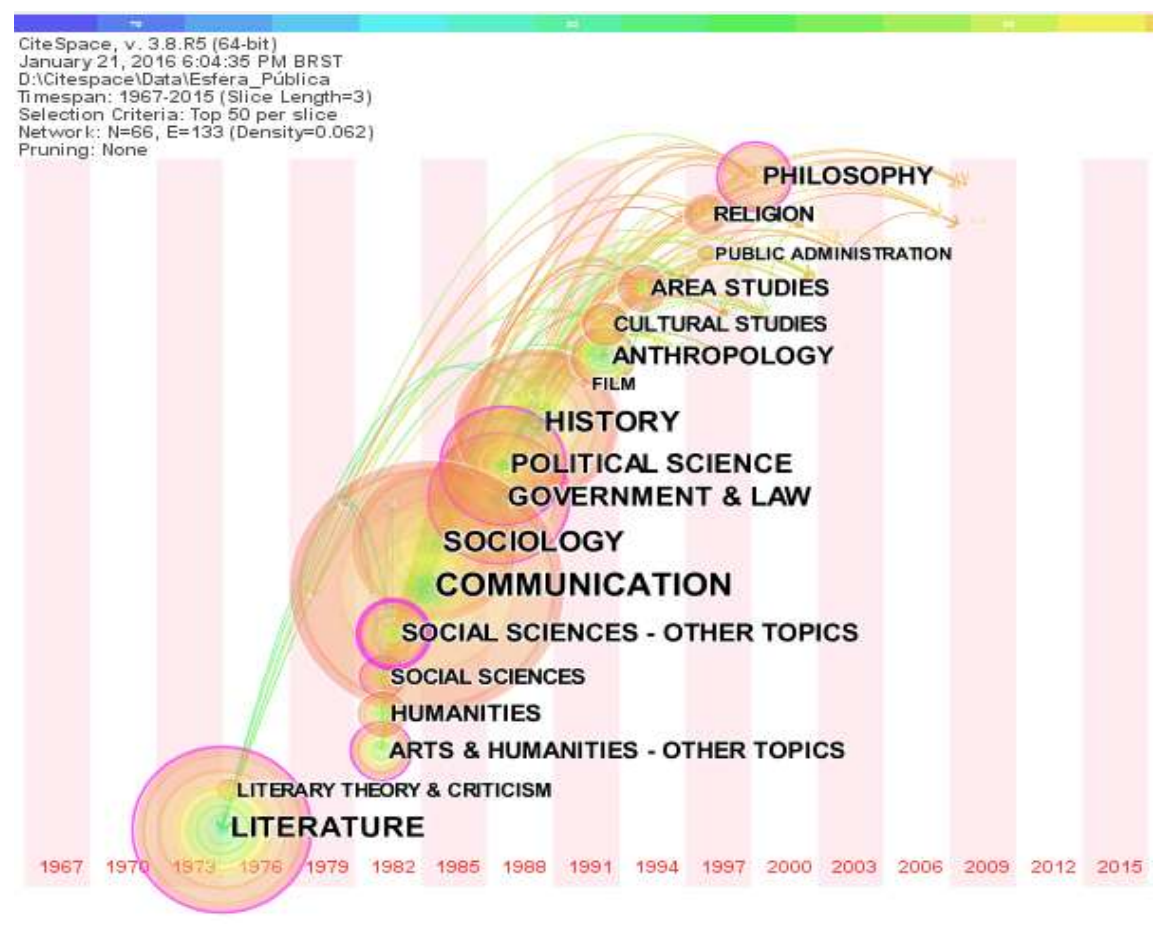

Os dados apresentados na Figura 2 permitem inferir que 0 termo "esfera pública" é utilizado em diversas áreas do conhecimento - com concentração de debate nas ciências humanas e sociais. Apesar de não aparecer na figura (na Figura 2 aparecem apenas categorias com 14 artigos ou mais), a categoria Urban Studies (Estudos Urbanos) foi a primeira, no ano de 1970, a publicar um artigo com o termo 'public sphere' no título, o trabalho de Beard (1970). Adiante, as categorias com maior número de artigos são Comunicação (154 artigos), Literatura (104), Sociologia
(101), História (96), Governo e Direito (87) e Ciência Política (76). A categoria Comunicação é a que possui o maior número de artigos (154). Esta abriga, por exemplo, o estudo de Papacharissi (2002) sobre esfera pública virtual - lembrando que esse foi o segundo artigo mais citado da frente de pesquisa. Interessante observar, também, que a categoria Filosofia apareceu apenas em 1998. Os pioneiros na área foram Bohman (1998), com o trabalho The globalization of the public sphere: cosmopolitanism publicity and cultural pluralismo, e Hauser (1998), com o trabalho Civil society 
and the principle of the public sphere. A categoria conta ainda com o artigo mais citado na busca, Religion in the public sphere (Habermas, 2006).

No que tange à produção acadêmica e à relação entre os países, observa-se na Figura 3 que os que apresentam maior número de publicações são Estados Unidos (266 artigos), Inglaterra (81), Austrália (36), Alemanha (36), Canadá (24), Holanda (13),
Itália (12), Noruega (11), Suíça (10) e África do Sul (10). A análise de países permite inferir se existe algum centro de debate sobre determinada temática. Cabe ressaltar, entretanto, que nesse estudo, há a limitação de os procedimentos já direcionarem as pesquisas na direção de periódicos de língua inglesa e indexados na Web of Science.

Figura 3: Rede de países (network of co-authors' countries)

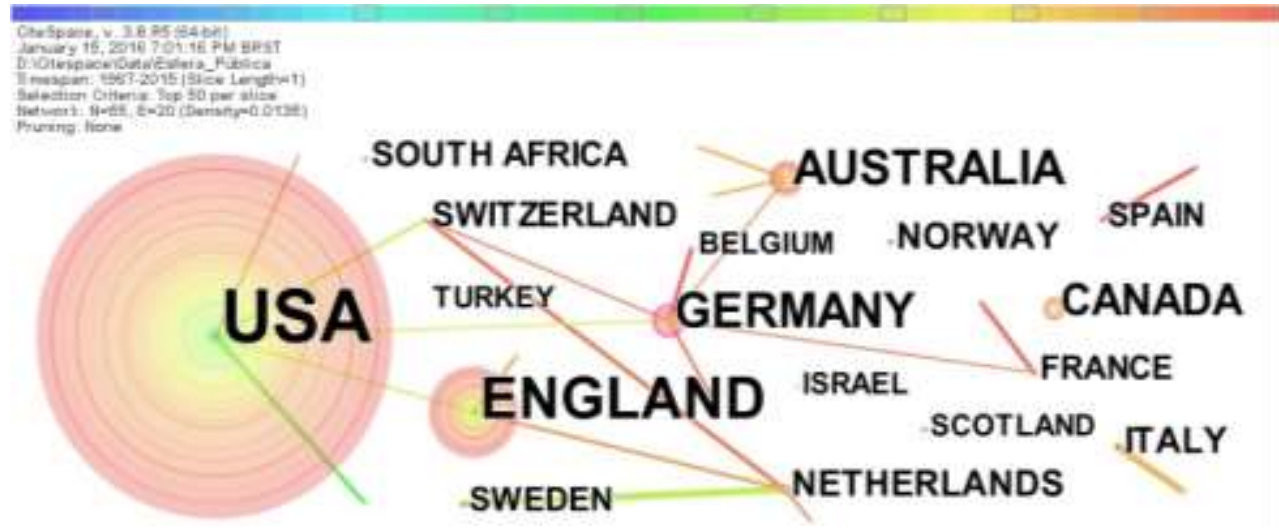

Nota: a rede é construída tendo por base apenas o país do primeiro autor do artigo.

Observa-se uma discrepância entre Estados Unidos e Inglaterra para os demais países - que em parte se deve a tendência da própria base (Prado et al., 2016). O trabalho de Papacharissi (2002) é o artigo mais citado dos Estados Unidos, seguido de Oliver e Myers (1999) e Fraser (2007), todos já abordados neste trabalho. Da Inglaterra o mais citado é New media, counter publicity and the public sphere (Downey \& Fenton, 2003). A Alemanha, apesar de ser país do autor do artigo mais citado na frente de pesquisa, Religion in the public sphere (Habermas, 2006), ocupa, em termos de quantidade de artigos, apenas a quarta posição (36 artigos).

Na sequência, a rede de palavras-chave (Figura 4) revela como a categoria esfera pública vem sendo utilizada em estudos de diferentes temáticas/temas. As dez mais frequentes foram: esfera pública (129 vezes), mídia (44), democracia (40), comunicação (31), política (30), internet (28), Habermas (24), sociedade civil (17), participação (17) e discurso (16).

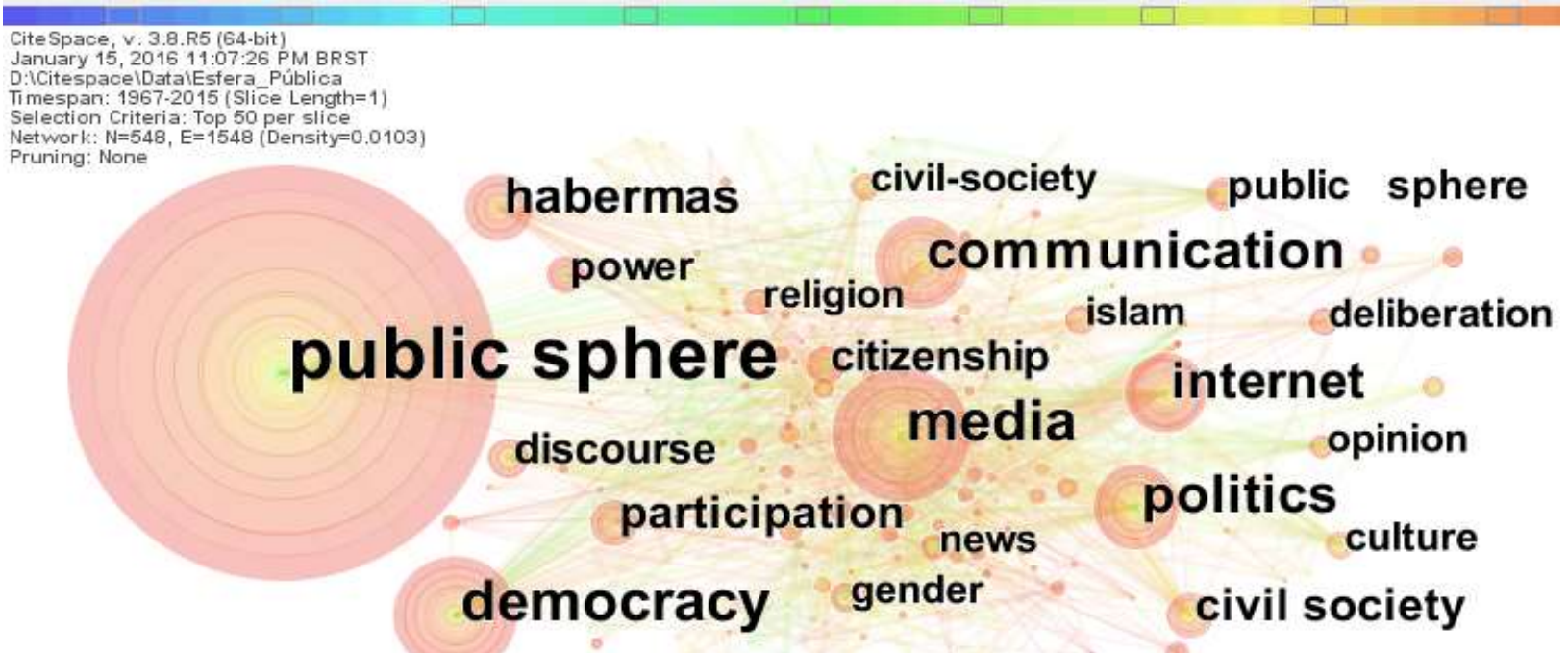

Para além do próprio termo esfera pública, observa-se que mídia, democracia e comunicação, política, internet, Habermas, participação, discurso e sociedade civil são destaques - essas questões comprovam as colocações de Avritzer e Costa (2004) e
Pereira (2012) sobre temáticas relacionadas ao debate acerca de esfera pública, especificamente, democracia, participação e sociedade civil. Diversos autores trabalham a questão dos meios de comunicação - mais recentemente os novos meios de comunicação 
(como a internet e as redes sociais) - e suas influências sobre a esfera pública - portanto, um tema forte na frente de pesquisa é a internet (Papacharissi, 2002, Medeiros, 2013), além das discussões desde Habermas e Arendt sobre democracia, Estado, sociedade e esfera pública (Dan, 2006, Goodman, 2010). Em relação à democracia, a categoria esfera pública é central para temáticas sobre modelos de democracia e, principalmente, em discussões relacionadas ao modelo de democracia deliberativa (Chambers, 2009, Lafont, 2009). Essa relação entre esfera pública e democracia pode explicar a presença de palavras como deliberação e discurso (Lafont, 2009). Outras categorias relacionadas à democracia e esfera pública são cidadania (Somers, 1995), sociedade civil (Ryoo, 2009) e participação (Nanz \& Steffek, 2004), que estão entre as principais palavras-chave.

Dentre os autores mais citados pelos artigos da busca (portanto, a base intelectual que é avaliada por meio da rede de cocitação de autores), constata-se que Jürgen Habermas é o mais citado, com mais de 700 menções. Um dos motivos é o fato de o autor possuir diversos livros que tratam diretamente da categoria esfera pública e que influenciaram fortemente este campo.
Importante observar, também, o grande número de citações de Nancy Fraser com mais de 200 citações. A autora é responsável por importantes críticas ao conceito de esfera pública habermasiano e trabalha ainda com questões relacionadas às desigualdades na esfera pública (Fraser, 1992) e esfera pública transnacional (Fraser, 2007) - o da década de 1990 aparece na Tabela 3. Hannah Arendt aparece, também, como uma das autoras mais citadas em decorrência de The human condition (Arendt, 1958). Craig Calhoun também é um autor bastante citado, sendo o segundo referenciado na base intelectual (trata de uma obra que ele organiza e também e autor de um texto) - conforme constata-se na Tabela 3 e também na frente de pesquisa com o texto Calhoun (2002). Outros são: Michael Warner autor de Publics and counterpublics (Warner, 2002) e Peter Dahlgren autor de The internet, public spheres, and political communication: dispersion and deliberation (Dahlgren, 2005).

Finalmente a figura 5 e a tabela 3 apresentam as obras mais referenciadas pelos 801 artigos - base intelectual do campo (Reference co-citation network). Esta destaca, também, a autoria completa e frequência de citações das obras mais referenciadas.

Figura 5: Rede de referências citadas (reference co-citation network)

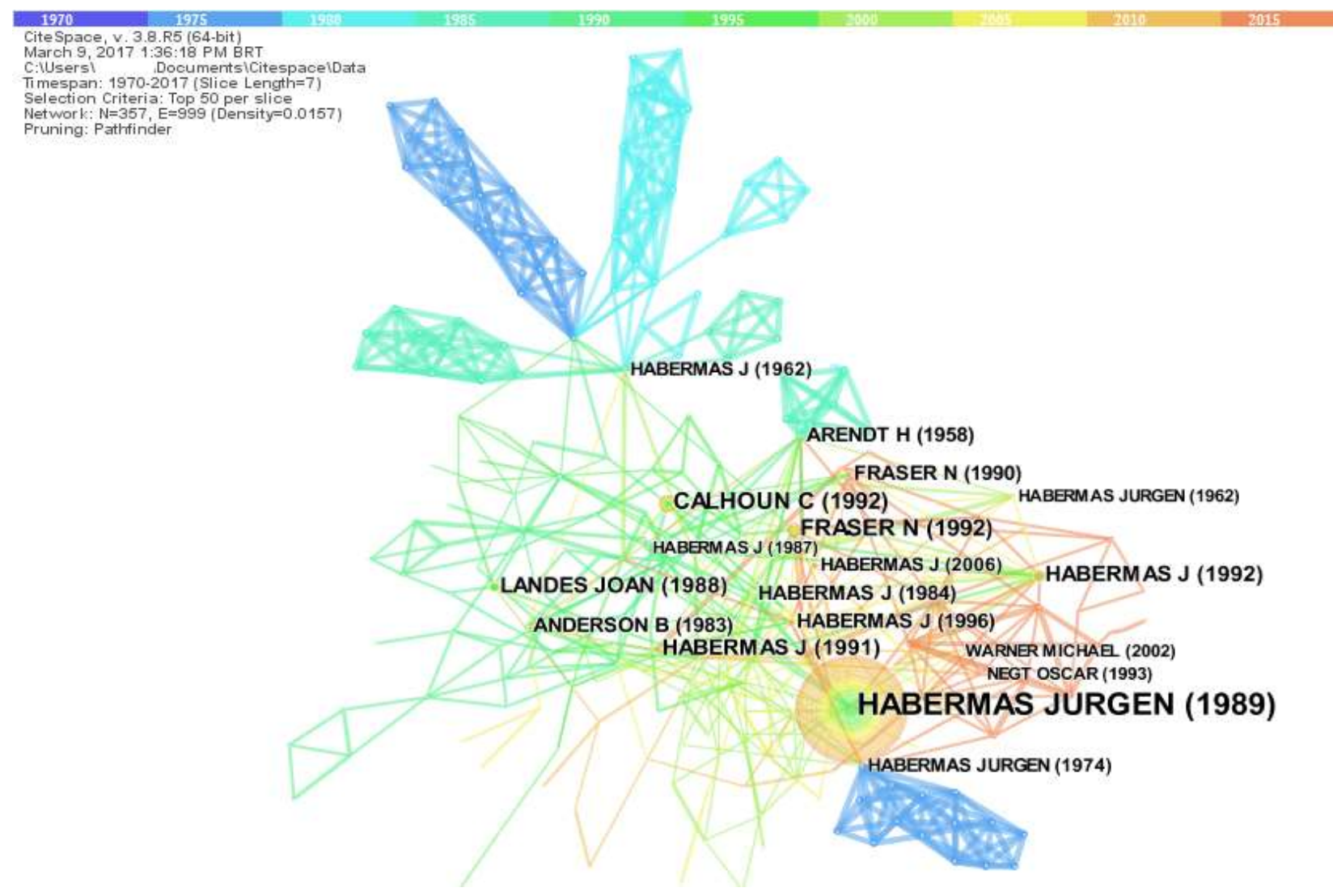

Nota: Na rede, aparece apenas o nome do primeiro autor do artigo e o ano de publicação - a autoria completa está apresentada na Tabela 3. A rede apresenta também a estrutura organizada com years per slice de 7 anos (Chen, 2006).

Em relação às obras, observa-se o grande número de citações de várias destas de Habermas. Sua obra mais citada é "Mudança estrutural da esfera pública" (1989), primeira tradução para o inglês da obra de 1962. Outras são o artigo Further Reflections on the
Public Sphere e o livro "Direito e democracia: entre facticidade e validade". 
Tabela 3: Obras mais referenciadas pelos 801 artigos - base intelectual do campo

\begin{tabular}{|c|c|c|}
\hline Título & Referência & Cit. \\
\hline The structural transformation of the public sphere: an inquiry into a category of bourgeois society & Habermas (1989) & 204 \\
\hline Habermas and the public sphere & Calhoun (1992) & 73 \\
\hline Rethinking the public sphere: a contribution to the critique of actually existing democracy & Fraser (1992) & 58 \\
\hline Further reflections on the public sphere & Habermas (1992) & 45 \\
\hline Women and the public sphere in the age of the french revolution & Landes (1988) & 42 \\
\hline The structural transformation of the public sphere: an inquiry into a category of bourgeois society & Habermas (1991) & 41 \\
\hline Between facts and norms: contributions to a discourse theory of law and democracy & Habermas (1996) & 39 \\
\hline The human condition & Arendt (1958) & 37 \\
\hline The theory of communicative action: $v .1$ & Habermas (1984) & 33 \\
\hline Imagined communities: reflections on the origin and spread of nationalism & Anderson (1983) & 30 \\
\hline Rethinking the Public sphere: a contribution to the critique of actually existing democracy & Fraser (1990) & 29 \\
\hline Strukturwandel der öffentlichkeit untersuchungen zu einer kategorie der büichen gesellchaft & Habermas (1962) & 27 \\
\hline Religion in the public sphere & Habermas (2006) & 24 \\
\hline The public sphere: an encyclopedia article & Habermas (1974) & 24 \\
\hline The theory of communicative action: $v .2$ & Habermas (1987) & 22 \\
\hline Publics and counterpublics & Warner (2002) & 20 \\
\hline Public sphere and experience: toward an analysis of the bourgeois ar & Negt and Kluge (1993) & 20 \\
\hline
\end{tabular}

Nota: Na tabela obras (artigos, livros e capítulo de livros) com pelo menos 20 citações ou mais.

A Tabela 3 revela que mesmo com a predominância das obras de Habermas (com obras bastante citadas em alemão e inglês) existem controvérsias, como as estabelecidas pelos textos Rethinking the public sphere: a contribution to the critique of actually existing democracy (Fraser, 1992), Publics and counterpublics (Warner, 2002) e Public sphere and experience: toward an analysis of the bourgeois and proletarian public sphere (Negt \& Kluge, 1993).

Figura 6: Frequência de citações das obras

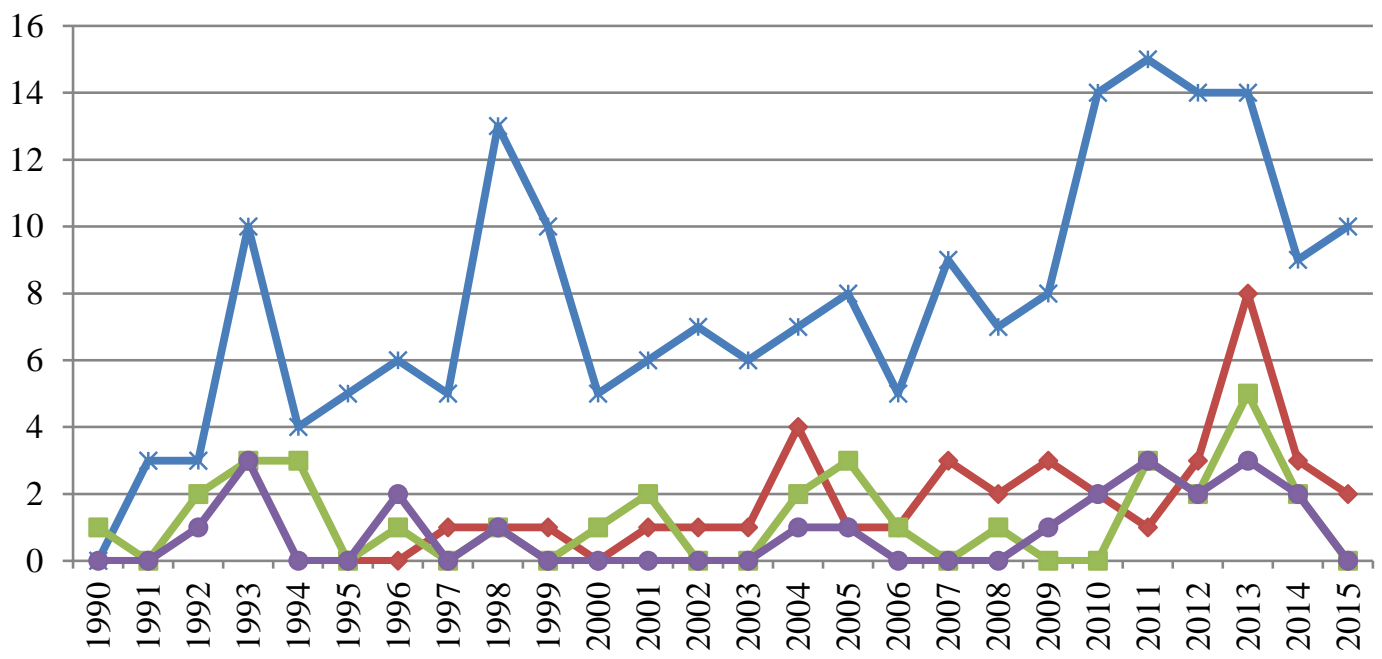

* Mudança Estrutural da Esfera Pública —Direito e Democracia

- Teoria da Ação Comunicativa vol. 1 - Teoria da Ação Comunicativa vol. 2

Nota: A figura apresenta a frequência de citações a partir do ano de 1990.

Adiante, apesar de escrita em 1962 e traduzida em 1989 para o inglês, a obra de Habermas continua, após mais de 50 anos, sendo bastante citada. Tendo em vista o autor e suas obras figurarem como as mais citadas, a Figura 5 apresenta o número de citações por ano das produções "Mudança Estrutural da Esfera Pública", "Direito e Democracia", "Teoria do Agir Comunicativo" Vol. 1 e Vol. 2. Destaca-se que "Mudança Estrutural da Esfera
Pública" continua sendo, com grande disparidade, o trabalho mais citado de Habermas. Entretanto, ao longo do tempo ele modificou seu conceito de esfera pública, incorporando críticas e reconhecendo limitações políticas-sociológicas e destacando que sua primeira formulação estava relacionada à sociedade burguesa do século XVIII (Lubenow, 2007; Fraser, 2007). Portanto, essas alterações devem ser observadas em obras como "Direito e 
Democracia”, mesmo que a obra década de 1960 seja a principal referência do campo esfera pública.
De forma ilustrativa, a Figura 6 traz a síntese da frente de pesquisa e base intelectual do campo de pesquisa em esfera pública.

Figura 6: Síntese dos resultados encontrados para a frente de pesquisa e base intelectual

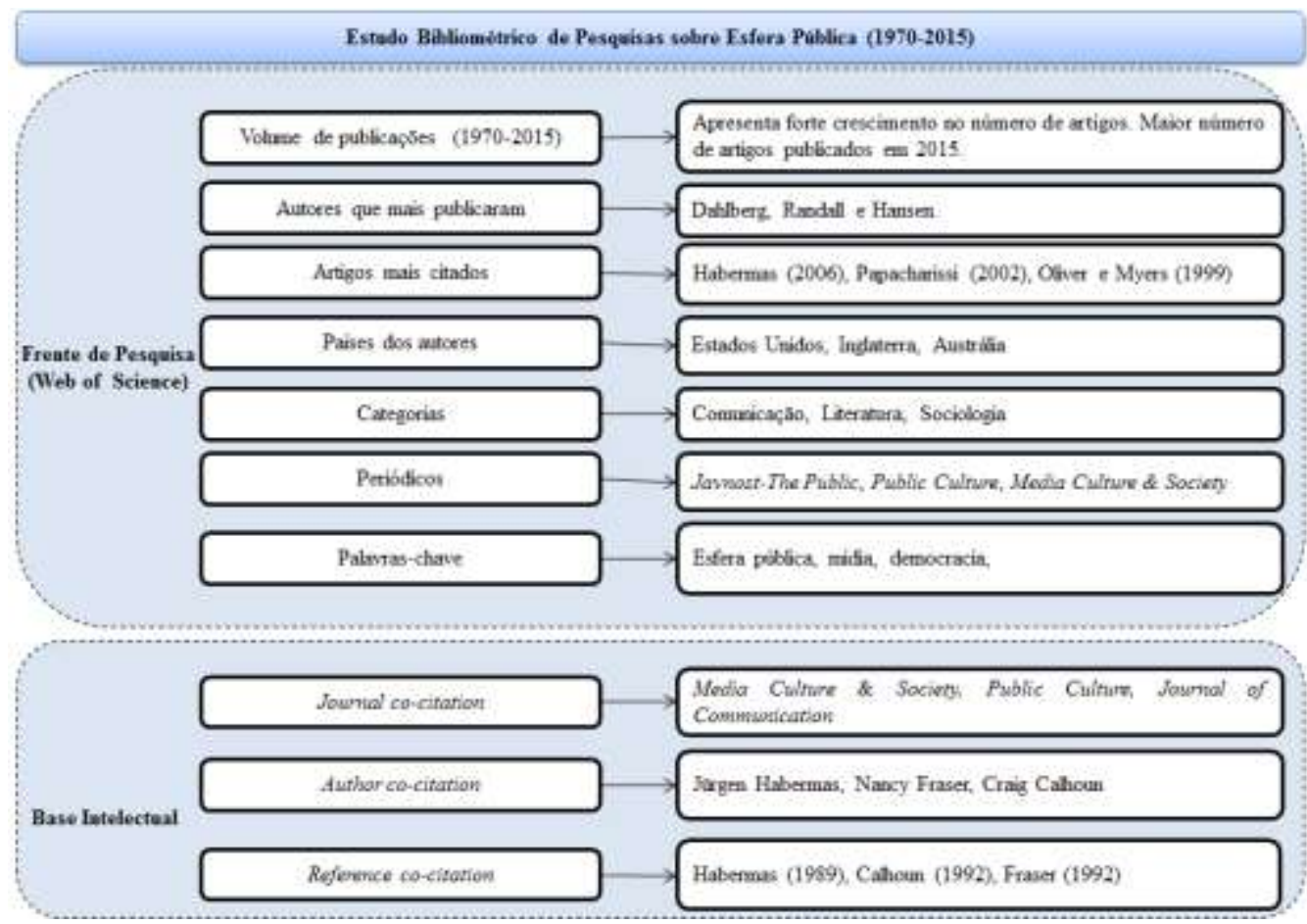

Nota: Na figura aparecem os três elementos com maior frequência.

Finalmente, constata-se que a produção científica sobre esfera pública está em ascensão e que o tema é plural (multidisciplinar) em suas abordagens, áreas de pesquisas e objetos de estudos. Contudo, mesmo com as controvérsias e críticas, Habermas ainda é a referência dos estudos sobre esfera pública.

\section{CONSIDERAÇÕES FINAIS}

O objetivo deste artigo foi analisar como se configura o campo de pesquisas sobre esfera pública, identificando tendências e características centrais. Em síntese, essa análise bibliométrica sobre esfera pública demonstra que o campo é interdisciplinar, amplo e que ainda está em crescimento - o que ocorreu principalmente a partir da década de 1990. Os dez artigos mais citados na base Web of Science destacam diversos temas como mídia, internet, cultura política, movimentos sociais e esfera pública transnacional (este último é central em três dos dez artigos mais citados). Esses temas podem ser pesquisados e aplicados em pesquisas de gestão social e administração pública no Brasil, afinal, temas relacionados a essas áreas do conhecimento são tangenciados nos estudos sobre esfera pública, no entanto, sem grande desenvolvimento ainda.

Observou-se que na frente de pesquisa não houve concentração das publicações em determinados autores, encontrando concentração no que tange ao país, no caso dos Estado Unidos. Também, constatou-se que, além de ser autor do artigo mais citado (Religion in the public sphere), Habermas aparece como a principal referência bibliográfica do campo com sua obra "Mudança Estrutural da Esfera Pública" de 1962 - que apesar das modificações é o texto mais citado - e seu nome está ainda entre as palavras-chave mais mencionadas. Portanto, é autor mais proeminente tanto da frente de pesquisa quanto da base intelectual. Nisso, percebe-se também que por meio de Habermas a tradição discursiva (Ferree et al., 2002) da esfera pública é dominante no campo. A disputa atual, apesar de desigual, parece ser entre a tradição discursiva (especialmente Habermas) e a tradição construcionista de Nancy Fraser, Seyla Benhabib e Iris Marion Young, influenciadas, dentre outros, por Michel Foucault e Hannah Arendt.

No que tange à frente de pesquisa, além de Habermas, são proeminentes os textos de Calhoun (1992) e Fraser (1992). De forma geral, observaram-se também posições divergentes sobre a validade do conceito, sobre a noção habermasiana de esfera pública, sobre sua efetividade e aplicabilidade as sociedades contemporâneas marcadas pelo pluralismo e uma diversidade de conflitos. As concepções de esfera pública na literatura permanecem, ainda, conforme também indicou Koçan (2008), marcadas por concepções micro e macro, descritivas e normativas, orientadas a fins e ao agir, mesmo que predominem, em decorrência de Habermas, as visões macro, normativa e orientada a fins (consensual, discursiva e deliberativa). 
Outras características e tendências encontradas foram a expressividade do número de artigos publicados pelo periódico Javnost - The Public - e por outros que possuem linhas de publicação voltadas para mídia, cultura e sociedade. Adiante, esfera pública é um conceito relevante em áreas como comunicação, literatura, história e ciência política. Assim, é possível afirmar que a categoria esfera pública é estudada em diferentes áreas de conhecimento e está intimamente relacionada com discussões sobre mídia, democracia, comunicação, internet, participação, dentre outras.

Finalmente, os resultados do presente trabalho são importantes para pesquisas sobre esfera pública em diferentes áreas de conhecimento, pois apontam qual autor mais citado, quais são os periódicos e países com maior número de publicações sobre a temática, além de apresentar as principais discussões, bem como contribuições e críticas sobre esfera pública - que podem orientar e embasar novas discussões teóricas e pesquisas empíricas. Esses elementos podem ser utilizados principalmente pelos campos da administração pública e gestão social, que ainda não avançaram tanto na literatura habermasiana, quanto nas demais vertentes, abordagens e tradições do entendimento da esfera pública.

Destacam-se três limitações principais: (a) o estudo bibliométrico foi realizado em apenas uma base de dados, que apesar de ser ampla privilegia a literatura dos Estados Unidos e Europa e que, portanto, torna-se importante uma revisão que englobe uma diversidade maior de trabalhos da América Latina, especialmente com a utilização de outras bases - a pesquisa mostra que alguns estudos sobre esfera pública já foram desenvolvidos tendo como locus a América Latina como Avritzer e Costa (2004) e Piccato (2010); (b) as análises foram mais descritivas, sendo que uma abordagem que explore as lacunas, críticas e diferentes perspectivas da esfera pública pode ser desenvolvida a partir do que foi apresentado; (c) não foram exploradas as diferenças e complementariedades ontológicas, epistemológicas e metodológicas dos artigos analisados (o que poderia gerar agrupamentos ou abordagens) e (d) não se buscou o entendimento da recepção da categoria esfera pública no Brasil, nem em países do Sul, usando a noção de Boaventura de Sousa Santos - lembrando do seu debate sobre esfera pública em Public sphere and epistemologies of the South (Santos, 2012).

Como agenda de pesquisa, indica-se, além de explorar as lacunas acima descritas: (i) ampliar as pesquisas bibliométricas, tendo em vista compreender a pluralidade das significações do público - a partir da consideração também das expressões espaço público, publicidade e publicização -; (ii) compreender a literatura de formação das esferas públicas na América Latina, principalmente aqueles países que foram colonizados em seu processo de formação; (iii) ampliar o debate sobre esfera pública transnacional e sua relação com as esferas públicas locais; e (iv) sistematizar relações entre perspectivas de gestão social e administração pública e as tradições do entendimento sobre esfera pública; e (v) analisar comparativamente como os diferentes conceitos de esfera pública, em diversos autores e abordagens, podem ser reconstruídos tendo em vista a compreensão dos processos econômicos, sociais e políticos em cursos atualmente no Brasil (como se percebe, vários elementos iniciais podem ser vistos neste estudo bibliométrico).

\section{REFERÊNCIAS BIBLIOGRÁFICAS}

Akhavan, P., Ebrahim, N. A., Fetrati, M. A., \& Pezeshkan, A. (2016). Major trends in knowledge management research: a bibliometric study. Scientometrics, 107(3), 1249-1264.

Alcântara, V. C. (2015). Mundo-da-vida e sistema: o locus da gestão social sob a abordagem habermasiana. Dissertação (Mestrado em Administração), Universidade Federal de Lavras, Lavras, Minas Gerais, Brasil.

Anderson, B. (1983). Imagined communities: Reflections on the origin and spread of nationalism. London: Verso.

Arendt, H. (1958). The human condition. Chicago: University of Chicago Press.

Avritzer, L., \& Costa, S. (2004). Critical theory, democracy, and the public sphere: concepts and uses in Latin America. Dados, 47(4), 703-728.

Beard, S. S. (1970). Commitment is a red herring a discussion of minority business development to explore the role of the private sector in the public sphere. Urban Affairs Review, 6(1), 8-21.

Bohman, J. (1998). The Globalization of the Public Sphere: Cosmopolitanism, Publicity, and Cultural Pluralism. The Modern Schoolman, 75(2), 101-117.

Calhoun, C. J. (1992). Habermas and the public sphere. Cambridge, MA: MIT press.

Calhoun, C. J. (2002). Imagining solidarity: Cosmopolitanism, constitutional patriotism, and the public sphere. Public culture, 14(1), 147-171.

Cançado, A. C., Pereira, J. R., \& Tenório, F. G. (2015). Gestão Social: epistemologia de um paradigma ( $2^{\mathrm{a}}$ ed.). Curitiba: Editora CRV.

Castells, M. (2008). The new public sphere: Global civil society, communication networks, and global governance. The annals of the american academy of Political and Social Science, 616(1), 78-93.

Chambers, S. (2009). Rhetoric and the public sphere: Has deliberative democracy abandoned mass democracy?. Political Theory, 37(3), 323-350.

Chen, C. (2004). Searching for intellectual turning points: Progressive knowledge domain visualization. Proceedings of the National Academy of Sciences, 101(suppl 1), 5303-5310.

Chen, C. (2006). CiteSpace II: Detecting and visualizing emerging trends and transient patterns in scientific literature. Journal of the American Society for information Science and Technology, 57(3), 359-377.

Dahlgren, P. (2005). The Internet, public spheres, and political communication: Dispersion and deliberation. Political communication, 22(2), 147-162.

Downey, J., \& Fenton, N. (2003). New media, counter publicity and the public sphere. New Media \& Society, 5(2), 185-202.

Ferree, M. M., Gamson, W. A., Gerhards, J., \& Rucht, D. (2002). Four models of the public sphere in modern democracies. Theory and society, 31(3), 289324.

Fraser, N. (1990). Rethinking the public sphere: A contribution to the critique of actually existing democracy. Social text, (25/26), 56-80.

Fraser, N. (1992). Rethinking the public sphere: a contribution to the critique of actually existing democracy. In: Calhoun, C. J. (Ed.). Habermas and the public sphere. Cambridge, MA: MIT Press, p. 107-142.

Fraser, N. (2007). Special section: Transnational public sphere: Transnationalizing the public sphere: On the legitimacy and efficacy of public opinion in a post-Westphalian world. Theory, culture \& society, 24(4), 7-30.

Goodman, D. (1992). Public sphere and private life: Toward a synthesis of current historiographical approaches to the old regime. History and theory, 1 20.

Goodman, R. T. (2010). In a state without state: Jean Said Makdisi's Beirut fragments as a thought experiment in public sphere disintegration. Contemporary Literature, 51(1), 27-57

Habermas, J. (1962). Strukturwandel der öffentlichkeit: untersuchungen zu einer kategorie der bürgerlichen gesellschaft. Frankfurt: Suhrkamp.

Habermas, J. (1974). The public sphere: An encyclopedia article. New German Critique, (3), 49-55.

Habermas, J. (1984). The theory of communicative action: reason and the rationalisation of society. (Vol. 1). Boston, MA: Beacon Press.

Habermas, J. (1987). The theory of communicative action: the critique of functionalist reason. (Vol. 2). Boston, MA: Beacon Press. 
Habermas, J. (1989). The structural transformation of the public sphere: an inquiry into a category of bourgeois society. Cambridge: MIT Press.

Habermas, J. (1992). Further reflections on the public sphere. In: Calhoun, C. J. (Ed.). Habermas and the public sphere. Cambridge, MA: MIT Press, p. 421461.

Habermas, J. (1996). Between facts and norms: contributions to a discourse theory of law and democracy. Cambridge, MA: MIT press.

Habermas, J. (2003). Mudança estrutural da esfera pública: investigações quanto a uma categoria da sociedade burguesa. Rio de Janeiro: Tempo Brasileiro.

Habermas, J. (2006). Religion in the public sphere. European journal of philosophy, 14(1), 1-25.

Habermas, J. (2012). Espaço Público (Um verbete de enciclopédia). Problemata: Revista Internacional de Filosofia, 3(2), 218-227.

Habermas, J. (1991). The structural transformation of the public sphere: An inquiry into a category of bourgeois society. Cambridge: MIT press.

Hauser, G. A. (1998). Civil society and the principle of the public sphere. Philosophy \& rhetoric, 31(1), 19-40.

Huang, P. C. (1993). "Public Sphere"/"Civil Society" in China? The Third Realm between State and Society. Modern China, 19(2), 216-240.

Knödler-Bunte, E. (1975). The proletarian public sphere and political organization: an analysis of Oskar Negt and Alexander Kluge's The Public Sphere and Experience. New German Critique, (4), 51-75.

Koçan, G. (2008). Models of public sphere in political philosophy. Eurosphere: Diversity and the European Public Sphere. 2008. Acessado em: <http://eurospheres.org/files/2010/08/Eurosphere_Working_Paper_2_Kocan. pdf $>$. Acessado em 20 de out. De 2016.

Koopmans, R. (2004). Movements and media: Selection processes and evolutionary dynamics in the public sphere. Theory and Society, 33(3-4), 367391.

Lafont, C. (2009). Religion and the public sphere: What are the deliberative obligations of democratic citizenship?. Philosophy \& Social Criticism, 35(1-2), 127-150.

Landes, J. B. (1988). Women and the public sphere in the age of the french revolution. Ithaca, New York: Cornell University Press.

Lavalle, A. G. (2002). Jürgen Habermas e a virtualização da publicidade. Revista Margem, 65-82.

Liu, G. (2013). Visualization of patents and papers in terahertz technology: a comparative study. Scientometrics, 94(3), 1037-1056.

Liu, Z., Yin, Y., Liu, W., \& Dunford, M. (2015). Visualizing the intellectual structure and evolution of innovation systems research: a bibliometric analysis. Scientometrics, 103(1), 135-158.

Lubenow, J. A. (2007). A categoria de esfera pública em Jürgen Habermas: para uma reconstrução da autocrítica. Cadernos de ética e filosofia política, 10(1), 103-123.

Lubenow, J. A. (2012). A esfera pública 50 anos depois: esfera pública e meios de comunicação em Jürgen Habermas em homenagem aos 50 anos de Mudança estrutural da esfera pública. Trans/Form/Ação, 35(03).

Malmberg, T. (2017). Studying the career of ideas as reception history: Habermas' Strukturwandel and finnish media studies, 1970s to 2010s. In Kommunikationswissenschaft im internationalen Vergleich (pp. 211-237). Springer Fachmedien Wiesbaden.

Medeiros, J. D. S. (2013). Considerations on the public sphere: social networks on the internet and political participation. Transinformação, 25(1), 27-33.
Nanz, P., \& Steffek, J. (2004). Global governance, participation and the public sphere. Government and opposition, 39(2), 314-335.

Negt, O. \& Kluge, A. (1993). Public sphere and experience: toward an analysis of the bourgeois and proletarian public sphere. Minneapolis: University of Minnesota Press.

Niazi, M., \& Hussain, A. (2011). Agent-based computing from multi-agent systems to agent-based models: a visual survey. Scientometrics, 89(2), 479 499.

Oliver, P. E., \& Myers, D. J. (1999). How events enter the public sphere: Conflict, location, and sponsorship in local newspaper coverage of public events 1. American Journal of Sociology, 105(1), 38-87.

Papacharissi, Z. (2002). The virtual sphere The internet as a public sphere. New media \& society, 4(1), 9-27.

Paris, R. (1975). Class structure and legitimatory public sphere: a hypothesis on the continued existence of class relationships and the problem of legitimation in transitional societies. New German Critique, (5), 149-157.

Perlatto, F. (2015). Seletividade da esfera pública e esferas públicas subalternas: disputas e possibilidades na modernização brasileira. Revista de Sociologia e Política, 23(53), 121-145.

Piccato, P. (2010). Public sphere in Latin America: a map of the historiography. Social History, 35(2), 165-192.

Pinto, C. F., Serra, F. R., \& Ferreira, M. P. (2014). A bibliometric study on culture research in International Business. Brazilian Administration Review, 11(3), 340-363.

Prado, J. W.; Alcântara, V. C,, Carvalho, F. M., Vieira, K. C., Machado, L. K. C., \& Tonelli, D. F. (2016). Multivariate analysis of credit risk and bankruptcy research data: a bibliometric study involving different knowledge fields (19682014). Scientometrics, 106(3), 1007-1029.

Ribeiro, P. H. G. O. (2012). Entre eclusas e espelhos: a esférica pública vista a partir de uma leitura crítica de Niklas Luhmann e de debates contemporâneos. Dissertação (Mestrado em Direito), Universidade de São Paulo, São Paulo, Brasil.

Ryoo, W. (2009). The public sphere and the rise of South Korean civil society. Journal of Contemporary Asia, 39(1), 23-35.

Santos, B. S. (2012). Public sphere and epistemologies of the South. Africa Development, 37(1), 43-67.

Silva, E. A. F.; Garcia, A. S.; Machado, J. C.; Cruz, E. S. T.; Pereira, J. R (2015). Evidências da categoria esfera pública Habermasiana: uma metasíntese de estudos qualitativos. Anais do XVIII Seminários em Administração. USP, São Paulo, Brasil.

Somers, M. R. (1995). What's political or cultural about political culture and the public sphere? Toward an historical sociology of concept formation. Sociological theory, 113-144.

Steward, B. (2004). Writing a literature review. British Journal of Occupational Therapy, 67(11), 495-500.

Susen, S. (2011). Critical notes on Habermas's theory of the public Sphere. Sociological Analysis, 5(1), pp. 37-62.

Tenório, F. G. (2005). (Re)visitando o conceito de gestão social Desenvolvimento em Questão, 3(2), 101-124.

Uchida, J. (2013). The public sphere in colonial life: residents' movements in Korea under Japanese rule. Past \& Present, 220(1), 217-248.

Warner, M. (2002). Publics and counterpublics. Public culture, 14(1), 49-90. 